\title{
Mean Reversion in Annual Earnings and Its Implications for Security Valuation
}

\author{
ROBERT LIPE \\ Associate Professor of Accounting, College of Business and Administration, University of Colorado, \\ Campus Box 419, Boulder, CO 80309-0419 \\ ROGER KORMENDI \\ Professor of Business Economics, School of Business Administration, University of Michigan, \\ Ann Arbor, MI 48109
}

\begin{abstract}
This article documents the long-horizon mean reverting character of annual earnings and tests the implications of such mean reversion for security valuation. First, both theory-based and nonparametric measures of earnings persistence decrease as the estimation order increases, revealing 40 percent less long-horizon persistence than expected under the commonly used random walk model. Second, the return responses to the earnings shocks are more closely related across firms to the higher-order measures of persistence that reflect significant longhorizon mean reversion. Third, the persistence measure derived from classical valuation theory outperforms the generic measure in explaining the return responses. Taken as a whole, these results provide evidence for significant mean reversion in the higher-order properties of earnings and for the stock market incorporating these properties in a manner consistent with classical valuation theory.
\end{abstract}

Key words: earnings persistence, mean reversion, security valuation, higher-order properties

\section{Introduction}

This article documents the mean reverting character in annual earnings that emerges from the higher-order times-series properties of earnings and assesses the implications of such mean reversion for security valuation. The time-series properties of earnings have long interested researchers in accounting, finance, and economics because of their role in valuation. Beaver (1970, p. 65), for example, argues that:

the valuation models developed in finance lend support to the notion that forecasting future profitability is an essential part of the valuation process. The forecasting process cannot proceed very far without additional knowledge of the underlying process generating earnings observations, since a knowledge of the underlying process is a prerequisite to the construction of an optimal forecasting system.

Until recently, investigations of the time-series properties of annual earnings have largely concentrated on the univariate behavior of earnings. This literature has concluded that the random walk model is a good average approximation of the earnings generating process, although several exceptions to this general model have been documented. ${ }^{1}$ 
A more recent line of research jointly addresses the time-series properties of earnings and security valuation. Theoretical models in Miller and Rock (1985) and Kormendi and Lipe (1987) demonstrate how the response of stock prices to unexpected earnings is directly determined by the time-series parameters of the earnings generating process (among other factors). ${ }^{2}$ For firms with more "persistent" processes, the current-period unexpected earnings implies a greater change in future profitability; thus, two firms with equal unexpected earnings would experience different abnormal returns if their earnings series were differentially persistent. Lipe (1986), Kormendi and Lipe (1987), Easton and Zmijewski (1989), and Collins and Kothari (1989) empirically document a positive relation between the return reactions to earnings (the so-called earnings response coefficient) and persistence. The results provide support both for the validity of classical valuation theory and for the importance of cross-firm differences in the earnings generating processes. While this research implies that the benchmark random walk model is not valid for each firm, the studies to date have not shown that the average firm-specific process differs significantly from the random walk.

Motivated primarily by a desire for parsimony, virtually all of the prior studies of the time-series properties of earnings have focused on low-order time-series models (either first- or second-order autoregressions or first-order moving averages). Yet recent empirical studies of stock prices (Fama and French, 1988) and GNP (Cochrane, 1988) illustrate how the higher-order autocorrelations of economic series can reveal noticeable mean reversion, even when the lower order properties do not. If corporate earnings exhibit similar higherorder mean reversion, then classical valuation theories would predict less of a stock price reaction to an earnings announcement. These observations motivate our investigation and the structure of our tests.

Two measures of persistence are used in this article-one a parametric measure based on classical valuation theory as exposited in Kormendi and Lipe (1987), and the other a nonparametric measure motivated by the work of Cochrane (1988), Campbell and Mankiw (1987, 1989), Kormendi and Meguire (1990), Liu and He (1991), and others. Both measures are estimated using different numbers of lags of the earnings data, which we refer to as varying the estimation order. We find that higher-orders of both the theory-based and nonparametric measures produce long-horizon forecasts of earnings that are on average 40 percent less than those implied by a random walk model. Since a one-dollar earnings shock in the current period does not increase long-horizon earnings forecasts by one dollar, the series exhibits significant partial mean reversion. ${ }^{3}$

Given the significant mean reversion evident in the higher-order properties of earnings, classical valuation theory would predict that higher-order persistence measures would explain more of the cross-sectional variation in the return responses to earnings shocks (commonly referred to in the accounting literature as the earnings response coefficient). Cross-firm rank correlations between these parameters show that both the theory-based and nonparametric persistence measures are significantly correlated with the earnings response coefficients, with the largest correlations occurring for estimation orders of four or more. As a further test of the classical theory, the explanatory power of the theory-based persistence measure is compared to that of the generic, nonparametric measure. The theory-based measures dominate in the context of these cross-firm correlations. Taken as a whole, the results provide evidence for the mean-reverting properties of earnings and for the stock market incorporating these properties in a manner consistent with classical valuation theory. 
The remainder of the article is organized into four sections. The first section motivates our investigation of the higher-order properties and uses the impulse response function to describe two measures of persistence. The second section describes the data, and the empirical results are presented in the third section. The last section summarizes the article.

\section{Persistence: Theory and Practice}

In this section, we first explain the theory-based and nonparametric measures of persistence. Then, the hypotheses for testing the importance of the higher-order properties of earnings are developed.

\subsection{The Concept of Persistence}

The persistence of an economic series describes how a current shock is expected to impact the whole stream of future realizations of the series. For a series $Y_{t}, t=0,1, \ldots$, define $C_{k}$ as the change in expectations of $Y_{t+k}$ given that a unit shock or innovation occurs in the series at time $t$. The vector $\mathbf{C}=\left(C_{1}, C_{2}, C_{3}, \ldots\right)$ fully describes the persistence properties of the series, and $C_{k}$ is the persistence of the series at horizon $k^{4}$

The persistence vector $\mathbf{C}$ is a function of the time-series parameters governing the evolution of $Y_{t}$. Consider the general ARIMA $(p, 1, q)$ model of a series,

$$
\Phi(L) \Delta Y_{t}=\theta(L) e_{t},
$$

where $\Phi(L)=1-\phi_{1} L-\ldots-\phi_{p} L^{p}, \Theta(L)=1-\theta_{1} L-\ldots-\theta_{q} L^{q}$, and $L$ is the lag operator. By inverting $\Phi(L)$, the differenced series is a function of all past shocks as follows:

$$
\Delta Y_{t}=G(L) e_{t}=\left(1+g_{1} L+g_{2} L^{2}+\ldots\right) e_{t},
$$

where $G(L)=\Theta(L) / \Phi(L)$. Equation (2) can be used to derive the effect of a unit shock at time $t$ (i.e., $e_{t}=1.0$ ) on expectations of $Y_{t+k}$ and follows:

$$
C_{k}=1+g_{1}+g_{2}+\ldots+g_{k} .
$$

Equation (3) is referred to as the impulse response function in the macroeconomics and econometrics literatures. See, for example, Diebold and Rudebusch (1989, p. 192), who argue that, "Any reasonable persistence measure must be related to ... $[G(L)]$, which completely characterizes the mapping from inputs $\left[e_{t}\right]$ to outputs $\left[Y_{t}\right]$."

Measuring persistence is a matter of assessing the impulse response function described above. However, because $\mathbf{C}$ is a vector-valued function, there is no unique scalar characterization of the general concept of persistence. Selecting an operational measure of persistence depends in part upon the context in which the question arises. If one were interested only in the short horizons, a first-order autoregressive or moving average parameter may be a 
reasonable representation of persistence. If one were interested in only the longest horizon, the asymptote of the impulse response function may be more relevant (e.g., Campbell and Mankiw, 1987, 1989). However, if one is interested in the valuation implications of earnings, then discounting the revisions in expectations is more natural.

\subsection{Measuring Persistence}

Our first measure is therefore taken from a model (based on classical valuation theory) developed in Kormendi and Lipe (1987). In that article, the relation between returns and earnings is modelled using three assumptions: 1) a firm's stock price is the present value of its expected future cash flows, ${ }^{5}$ and hence returns are equal to the revisions in expected future cash flows based on new information, 2) the present value of the revisions in expected cash flows conditional on the earnings shock is equal to the present value of the revisions in expected earnings, ${ }^{6}$ and 3 ) earnings can be represented by a univariate ARIMA model. Under these assumptions, the relation between returns and earnings is a function of the present value of $C_{k}$ summed over $k=1, \ldots, \infty$, which Kormendi and Lipe denoted as $P V R$ for present value of revisions.

$$
P V R=\sum_{k=1}^{\infty} \beta^{k} C_{k}
$$

where $\beta=1 / 1+r, r$ is the appropriate rate for discounting expected future earnings, and $C_{k}$ captures the revision in expected earnings at $t+k$ due to an earnings shock at $t$.

Kormendi and Lipe drew from Flavin (1981) to show that for an ARIMA $(p, 1,0)$ model, PVR is a function of the autoregressive parameters as follows (Kormendi and Lipe, 1987, pp. 329-330):

$$
P V R=\frac{1}{(1-\beta)\left[1-\sum_{j=1}^{p} \beta^{j} \phi_{j}\right]}-1 .
$$

More recently, Collins and Kothari (1989, p. 148) adapt Flavin's approach to show that for the general ARIMA $(p, d, q)$ model,

$$
P V R=\frac{1-\sum_{i=1}^{q} \beta^{i} \theta_{i}}{(1-\beta)^{d}\left[1-\sum_{j=1}^{p} \beta^{j} \phi_{j}\right]}-1 .
$$


In this article, we set $d=1$ and $q=0$, and focus our investigation on the effects of changing $p$, the order of the ARIMA $(p, 1,0)$ model. ${ }^{7}$ To indicate that our estimates of $P V R$ are based on different orders, we will use the notation $\widehat{P V R}_{p}$. If the earnings generating process exhibits systematic higher-order properties, then the ability of $\widehat{P V R}_{p}$ to measure the true $P V R$ should increase with $p$. On the other hand, if the estimation errors in the higher-order autoregressive parameters are large, then more parsimonious models may provide more accurate estimates.

While $P V R$ is based on classical valuation theory, it still is only one of many potential scalar representations of the impulse response function. Therefore, we also examine the scaled variogram, a nonparametric statistic used in the macroeconomics and econometrics literatures. ${ }^{8}$ The scaled variogram is based on an elementary property of random walks. In population, the variance of the differences of a random walk at the $k$ th lag is $k$ times the variance of the differences at lag one. For any time series, $Y_{t}, t=0, \ldots, n$, let $\sigma^{2}(k)$ $=\sigma^{2}\left(Y_{t}-Y_{t-k}\right)$ denote the variance of the difference of $Y_{t}$ at the $k$ th lag. Then the $k$ th ordindate of the scaled variogram is $R(k)=\sigma^{2}(k) / k \sigma^{2}(1)$. To derive a small sample estimator for $R(k)$, we first estimate $\sigma^{2}(k)$ as

$$
\hat{\sigma}^{2}(k)=\sum_{t=k}^{n} \frac{\left[Y_{t}-Y_{t-k}-\frac{k}{n}\left(Y_{n}-Y_{0}\right)\right]^{2}}{(n-k)},
$$

where $n+1$ is the sample size, yielding $n$ first differences. The estimated $k$ th ordinate of the scaled variogram is then

$$
\hat{R}(k)=\frac{\hat{\sigma}^{2}(k)}{k \hat{\sigma}^{2}(1)} \frac{n-1}{(n-k)} \text {. }
$$

The $(n-1) /(n-k)$ is a correction for the bias caused by the overlap in consecutive differences. The expected value of $R(k)$ computed from a random walk is 1.0 , for all $k$. If the series contains a unit root, then $R(k)$ has a positive asymptote. If the asymptote lies between zero and one, it can be interpreted as the fraction of the variance of a series due to permanent shocks. If no unit root is present, $R(k)$ asymptotes to zero.9

Cochrane (1988) shows that in population, $R(k)$ is a linear combination of the first $k-1$ autocorrelations of the differenced series as follows:

$$
R(k)=1+2 \sum_{j=1}^{k-1} \frac{k-j}{k} \rho(j)
$$

where $\rho(j)$ is the $j$ th autocorrelation. If the higher-order properties of earnings are important, then the estimated scaled variogram should provide more accurate measures of persistence as the order, $k$, increases.

$\widehat{P V R}_{p}$ and $\hat{R}(k)$ are related measures of persistence. Comparing (5) and (9) shows that both persistence measures incorporate more of the time-series behavior of earnings as the estimation order ( $p$ or $k$ ) increases. Since both measures discount the impact of higher-order 
autocorrelations, they are natural choices given our interest in the valuation implications of earnings. For example, the magnitude of $\widetilde{P V R}_{p}$ reflects the dollar impact of current period earnings news on forecasts of long-term profitability. Other statistical methods can describe the time-series properties of earnings and test whether they differ from a random walk, but the resulting statistics are not as economically meaningful. Note that since $\hat{R}(2)$ is the ratio of the variance of the second differences to that of the first differences, it captures the firstorder properties of differenced earnings. For the theoretical persistence measure, the firstorder properties are captured by $\widehat{P V R}_{1}$. Therefore, $\widehat{P V R}_{p}$ and $\hat{R}(k)$ are based on similar estimation orders when $k=p+1$.

Whether $\widehat{P V R}_{p}$ or $\hat{R}(k)$ is a better measure of persistence depends upon the context and can only be answered empirically. If the classical valuation theory used to derive $P V R$ is reasonable, then $\widehat{P V R}_{p}$ should dominate $\hat{R}(k)$ in explaining cross-sectional variation in the response coefficients. On the other hand, $\hat{R}(k)$ could dominate $\widehat{P V R}_{p}$ either because the basic assumptions of the classical valuation theory are violated or because of misspecifications in the time-series model of earnings. Since the computation of the scaled variogram in Equation (8) does not require estimation of an ARIMA model, $\widehat{P V R}_{p}$ could contain specification errors (e.g., ignoring moving-average parameters) that will not exist in $\hat{R}(k) .^{10}$

\subsection{Testing for Long-Horizon Mean Reversion in the Higher-Order Properties of Annual Earnings}

In his investigation of the persistence properties of US GNP, John Cochrane (1988) finds that the higher-order autocorrelations of US GNP are small and would be ignored by most traditional time-series procedures. "But all autocorrèlations enter into [persistence] so a large number of small high-order autocorrelations can offset a few large low-order autocorrelations," (p. 914). Indeed, the autocorrelations at higher-orders are predominantly negative, which implies that GNP is substantially less persistent than one would expect based on only the low-order autocorrelations.

To test the importance of the mean reverting properties of earnings and their roles in firm valuation, we modify the estimating equations in Kormendi and Lipe (1987, p. 334) to accommodate the use of autoregressive models with varying estimation orders. Letting $a$ denote the coefficient relation stock returns to unexpected earnings, we use the following two equation system to estimate $\hat{a}_{p i}$ and $\widehat{P V R}_{p i}$ for each firm, $i$, and order, $p:{ }^{11}$

$$
\begin{gathered}
R_{i t}=\frac{b_{1 i}}{P_{i t-1}}+a_{p i} \frac{e_{p i t}}{P_{i t-1}}+U R_{i t} \\
\Delta X_{i t}=b_{2 i}+\sum_{j=1}^{p} \phi_{j i} \Delta X_{i t-j}+e_{p i t} .
\end{gathered}
$$

where $R_{i t}$ is the percentage return for firm $i$ in year $t, \Delta X_{i t}$ is the change in earnings, and $P_{i t-1}$ is the stock price for firm $i$ at the beginning of year $t$. 
Using the resulting estimates of $\hat{a}_{p}, \widehat{P V R}_{p}$, and $\hat{R}(k)$, we examine three primary issues:

1) If an important mean-reverting character emerges from the higher-order properties of earnings, then the theory-based persistence measure will be sensitive to the length of the estimation horizon. In particular, if the higher-order autocorrelations are predominantly negative (consistent with the mean reversion observed in other economic series), then

H1a: $P V R_{p}$ decreases as $p$ increases.

A more explicit test for mean reversion is to compare the observed theory-based and nonparametric persistence measures to the benchmark random walk model. Using superscript $R W$ to indicate the random walk, we test

H1b: $P V R_{p}<P V R_{p}^{R W}$ for all $p$ and $R(k)<R(k)^{R W}$ for large $k^{12}$

2) Under the joint hypothesis that the higher-order mean reverting properties of earnings are important and that classical valuation theory is descriptive, the higher orders of both the theory-based and nonparametric persistence measures should explain more of the cross-firm variation in the return response to earnings, or

$\mathrm{H} 2$ : $\operatorname{corr}\left(a_{p}, P V R_{p}\right)$ increases with $p$, and $\operatorname{corr}\left(a_{p}, R(k)\right)$ increases with $k$.

Essentially, the accuracy of the empirical proxies should increase as $p$ or $k$ approaches the most useful order for assessing the valuation implications of earnings. The joint hypothesis could fail because the higher-order properties are unimportant or because stock prices may be inconsistent with classical valuation theory. For instance, if the stock market overemphasizes short-run performance (as is sometimes argued in the financial press), then the correlation between $\widehat{P V R}_{p}$ and $\hat{a}_{p}$ may be a decreasing function of $p$, even though the higher-order properties of the earnings generating process are important.

3) As a direct test of whether classical valuation theory characterizes the relation between earnings and returns, the relative performance of the theory-based and the nonparametric measures are compared. Classical theory predicts that more of the cross-firm variation in $\hat{a}_{p}$ should be explained by $\widehat{P V R}_{p}$ than by $\hat{R}(k)$. Thus, we test the following pair of hypotheses:

H3a: $\operatorname{corr}\left(a_{p}, P V R_{p}\right)>\operatorname{corr}\left(a_{p}, R(k)\right)$, and

H3b: $\operatorname{corr}\left(a_{p}, P V R_{p} \mid R(k)\right)>0$, and $\operatorname{corr}\left(a_{p}, R(k) \mid P V R_{p}\right)=0$.

\section{The Data}

The data consist of annual corporate earnings for 118 calendar-year firms with complete data for the period 1947-1985.13 Quarterly data are not used because the purpose of the study is to assess the behavior of the earnings-generating process over a horizon of several years. ${ }^{14}$ The earnings number (denoted $X_{i t}$, for firm $i$ in year $t$ ) is the real, firm-specific earnings, as defined in Kormendi and Lipe (1987). The primary earnings per share (before 
extraordinary items and discontinued operations) are adjusted for stock splits and stock dividends. These numbers are then deflated by the CPI, and the differenced real earnings are regressed on the differenced real earnings for the Standard and Poors' industrials index; the residuals are our measures of $X_{i t}$.

The empirical measure of returns, $R_{i t}$, is the residual from an annual market model in which the real percentage return for firm $i$ 's common stock in year $t$ is regressed on the real percentage change in the CRSP value-weighted market index. ${ }^{15}$ The annual returns are cumulated from April of year $t$ until March of year $t+1$, because the sample firms all have December 31 year-ends. $P_{i t-r}$ is the real stock price at the beginning of the year $t$ cumulation period.

\section{Empirical Results}

We now turn to our empirical results. First, we characterize the persistence of annual earnings using various estimation orders for both the theory-based and nonparametric measures. Then, the response coefficients and their relation with $\widetilde{P V R}_{p}$ are examined. We also relate the nonparametric persistence measure to the response coefficient and test whether it is dominated by the theory-based measure of persistence. In a final subsection, we discuss how our results pertain to two issues currently being debated in the literature. Note that while we estimated all of the parameters for the first through tenth orders, we find that most of the improvements from incorporating the higher-orders occur by the fourth order. Therefore the tables which follow report $\widehat{P V R}_{p}, \hat{R}(p+1)$, and $\hat{a}_{p}$ for $1 \leq p \leq 4$. To illustrate the effects of using even higher orders, we also report results for the eighth order. Except where explicitly noted, the abridged results reported in the tables are representative of the evidence from all 10 estimation orders.

\subsection{Illustrating the Long-Horizon Mean Reverting Character in the Higher-Order Properties}

Table 1 contains descriptive statistics for the persistence measures across the 118 sample firms. Since the means and standard deviations may be influenced by outliers and skewness of the distributions, we focus on the medians and interquartile ranges. Panel A describes $\widehat{P V R}_{p}$ based on the autoregressive parameters that come from jointly estimating equations (10) and (11) for each firm. ${ }^{16}$ The calculation of $\widehat{P V R}_{p}$ uses an interest rate of ten percent. ${ }^{17}$ In Table $1, \widetilde{P V R}_{1}$ has a median of 8.96 . The median of $\widetilde{P V R}_{4}$ is 6.33 , implying that forecasts of the present value of revisions in expected future earnings decline by almost 30 percent for fourth-order as opposed to first-order models. Also, this persistence measure exhibits some decline beyond the fourth order as the median of $\widehat{P V R}_{8}$ is 5.21. But note that including the second- through fourth-order autoregressive parameters accounts for more of the decline than the fifth- through eighth-order parameters. Finding smaller $\widehat{P V R}_{p} \mathrm{~s}$ for larger values of $p$ implies that the earnings generating processes of these firms exhibit partial mean reversion, consistent with $\mathrm{Hla}$. The scaled variograms are summarized in panel $\mathrm{B}$ of Table 1 . The median of $\hat{R}(2)$ is .87 compared to .46 for $\hat{R}(9)$. Note that evidence from even higher orders (not reported) indicates that the medians of $\widehat{P V R}_{8}$ and $\hat{R}(9)$ represent the asymptotes of the persistence measures. 
Table 1. Summary statistics for the theory-based and nonparametric persistence measures. Medians, interquartile ranges (IQ Range), means, and standard deviations of the theorybased $\left(\widehat{P V R}_{p}\right)$ and the nonparametric $(\hat{R}(k))$ persistence measures, computed across 118 firms. Measures are estimated using data from 1947-1985 for each firm.

\begin{tabular}{lcccc}
\hline Parameter & Median & IQ Range & Mean & Std Dev \\
\hline \multicolumn{5}{c}{ Panel A: Theory-Based Persistence } \\
$\widehat{P V R}_{1}$ & 8.96 & 2.91 & 9.68 & \\
$\widehat{P V R}_{2}$ & 7.78 & 2.83 & 8.75 & 3.02 \\
$\widehat{P V R}_{3}$ & 7.15 & 2.87 & 8.03 & 3.40 \\
$\widehat{P V R}_{4}$ & 6.33 & 3.02 & 7.52 & 3.69 \\
$\widehat{P V R}_{8}$ & 5.21 & 3.76 & 6.67 & 4.25 \\
& & & & 5.46 \\
$\hat{R}(2)$ & Panel B: Nonparametric Persistence Measures & \\
$\hat{R}(3)$ & 0.87 & 0.34 & 0.91 & \\
$\hat{R}(4)$ & 0.76 & 0.40 & 0.85 & 0.26 \\
$\hat{R}(5)$ & 0.67 & 0.37 & 0.75 & 0.34 \\
$\hat{R}(9)$ & 0.60 & 0.35 & 0.68 & 0.38 \\
\hline
\end{tabular}

${ }^{1} \widehat{P V R}_{p i}$ is derived for firm $i$ and estimation order $p$ from the autoregressive parameters $\left(\hat{\phi}_{j i}\right)$ that are estimated using Equations $(10)$ and (11) as follows:

$$
\widehat{P V R}_{p i}=\frac{1}{(1-\beta)\left[1-\sum_{j=1}^{p} \beta^{j} \hat{\phi}_{j i}\right]}-1
$$

$\beta=1 / 1+r ;$ we assume $r=10 \%$.

${ }^{2}$ The nonparametric persistence measure is calculated for each firm as follows:

$$
\hat{R}(k)_{i}=\frac{\hat{\sigma}_{i}^{2}(k)}{k \hat{\sigma}_{i}^{2}(1)} \frac{n-1}{(n-k)} .
$$

To examine the similarities between $\widehat{P V R}_{p}$ and $\hat{R}(k)$, Table 2 presents cross-firm, Spearman rank correlations between the two measures. Every correlation is greater than .40 and is significantly positive. Note that for each $\widehat{P V R}_{p}$, the largest correlation (the boldface numbers in the table) occurs for $\hat{R}(p+1)$. In these five cases, the correlations range from .958 to .856 . This is consistent with our earlier observation that $\widetilde{P V R}_{p}$ and $\hat{R}(p+1)$ are based on similar estimation orders. We conclude that $\widehat{P V R}_{p}$ and $\hat{R}(k)$ appear to be measuring a similar phenomenort.

The declining $\widehat{P V R}_{p}$ in Table 1 implies that the higher-order properties of earnings exhibit mean reversion. In particular, the current-period earnings shock has a smaller effect on expectations of future earnings in the higher-order models. To further illustrate this effect, we compute the impulse response functions, $C_{k}$, based on the estimated autoregressive parameters, $\hat{\phi}_{j i}$. From an analyst's point of view, this describes how a one-dollar shock in period $t$ affects the forecast of earnings in period $t+k$. Table 3 reports these forecast revisions for short (one year), medium (five year), and long (20 year) horizons. The first row of Table 3 shows that, for the first-order autoregressive model, the medians of the 
Table 2. Spearman rank correlations between the theory-based $(\widehat{P V R})$ and the nonparametric $(\hat{R}(k))$ persistence measures, computed across 118 firms. Measures are estimated using data from 1947-1985 for each firm. Critical value ( $p$-level) for one-tailed test: .286 (.001).

\begin{tabular}{cccccc}
\hline Parameters & $\widehat{P V R}_{1}$ & $\widehat{P V R}_{2}$ & $\widehat{P V R}_{3}$ & $\widehat{P V R}_{4}$ & $\widehat{P V R}_{8}$ \\
\hline$\hat{R}(2)$ & .958 & .693 & .542 & .483 & .409 \\
$\hat{R}(3)$ & .844 & .885 & .693 & .630 & .520 \\
$\hat{R}(4)$ & .729 & .833 & .856 & .781 & .606 \\
$\hat{R}(5)$ & .582 & .737 & .846 & .874 & .673 \\
$\hat{R}(9)$ & .523 & .666 & .692 & .772 & .872 \\
\hline
\end{tabular}

The numbers in boldface are the maximum correlations in each column.

Table 3. Median forecast revisions implied by various estimation orders. Each column contains $C_{k}$, the revision in expected future earnings given a $\$ 1$ current-period shock. The three forecast horizons are 1 year ahead (short), 5 years ahead (medium), and 20 years ahead (long). The revision is computed based on the autoregressive parameters $\left(\hat{\phi}_{j i}\right)$ estimated using data from 1947-1985 in Equation 11. A separate revision is computed for each estimation order for each of the 118 firms, and the crossfirm median is reported.

\begin{tabular}{cccc}
\hline & \multicolumn{3}{c}{ Horizon Length } \\
\cline { 2 - 4 } Estimation Order & Short & Medium & Long \\
\hline 1 & .882 & .894 & .894 \\
2 & .861 & .784 & .784 \\
3 & .804 & .685 & .718 \\
4 & .804 & .584 & .634 \\
8 & .771 & .369 & .589 \\
\hline
\end{tabular}

The computation of $C_{1}$ is as follows: (1) set $X_{t}$ (and therefore, $\Delta X_{t}$ ) equal to 1.0 for $t=0$ and 0.0 for all $t<0,(2)$ compute $\Delta X_{1}$ based on $\Delta X_{1-j}$ and $\hat{\phi}_{j i}$ as per Equation 11, and (3) add $\Delta X_{1}$ to $X_{0}$, which yields the revision in expectations of $X_{1}$ due to a unit shock at $t=0$. The longerhorizon values of $C_{k}$ are obtained by iterating this procedure.

impulse function are relatively stable at approximately .89 for all horizons. Thus, a onedollar shock in year $t$ leads to an $\$ .89$ revision in expected earnings in all future years, which is close to the dollar-for-dollar random walk prediction. For a fourth-order autoregressive model, however, the medians of the medium- and long-horizon forecast revisions are approximately .6. Incorporating the higher-order properties of earnings thus implies long-horizon forecast revisions of about 40 percent less than those of a random walk. In this regard, we find evidence of mean reversion in the higher-order properties of earnings in much the same way as Cochrane does for US GNP or as Fama and French do for stock prices. Note, however, that there is only partial mean reversion, in that the long-horizon forecast asymptotes around .6 and not zero. ${ }^{18}$ 


\subsection{Formal Tests of Long-Horizon Mean Reversion}

Hypothesis Hib represents a more formal test of mean reversion in which the observed properties of earnings are compared to those expected under the random walk, the benchmark model from the univariate time-series literature. Theoretically, a random walk series has $P V R=10.0$ (assuming $r=10 \%$ ) and $R(k)=1.0$. Since deriving standard errors for testing the random walk hypothesis in small samples is not feasible due to the skewness of the distributions (see Kormendi and Meguire, 1990), we test this through Monte Carlo methods. We simulate 500 random walk series of 39 observations each and calculate $\widehat{P V R}_{p}^{R W}$ and $\hat{R}(k)^{R W}$ for each series at each order. The distributions of the actual and simulated persistence measures are then compared to test whether the properties of earnings at various orders are consistent with the random walk.19

Table 4 describes the persistence measures for the simulated random walk data. The medians of $\widehat{P V R}_{p}^{R W}$ decrease slightly as $p$ increases, going from 9.87 to 7.99. A similar pattern is observed for $\hat{R}(k)^{R W}$ in panel $\mathrm{B}^{20}$ The persistence measures for actual earnings in Table 1, however, are much smaller than those in Table 4. At the first order, the theorybased measure for actual earnings in 8.96 or about 10 percent less than $\widehat{P V R}_{1}^{R W} . \widehat{P V R}_{4}$ is 27 percent less than $\widehat{P V R}_{4}^{R W}$. For the scaled variogram, the median of $\hat{R}(9)$ is .46 , implying that only half of the variance in earnings is due to permanent shocks. Further, the persistence of actual earnings is more than 40 percent less than that of the simulated random walk (.46 versus .89$)$.

Since the 118 empirical series and the 500 simulated series provide two independent samples of persistence measures, the Mann-Whitney $U$ test can be used to formally compare

Table 4. Summary statistics for the persistence measures from simulated random walk data. Medians, interquartile ranges (IQ Range), means, and standard deviations of the theory-based ( $\left.\widetilde{P V R} R_{p}^{R W}\right)$ and the nonparametric $\left(\hat{R}(k)^{R W}\right)$ persistence measures, computed across 500 sets of 39 simulated observations. Also Mann Whitney tests comparing the measures from the empirical and simulated data. ${ }^{1}$

\begin{tabular}{lccccr}
\hline Parameter & Median & IQ Range & Mean & Std Dev & MW Z-stat \\
\hline \multicolumn{5}{c}{} & Panel A: Theory-Based Persistence Measure \\
$\widehat{P V R}_{1}^{R W}$ & 9.87 & 1.87 & 10.03 & 1.62 & -4.46 \\
$\widehat{P V R}_{2}^{R W}$ & 9.50 & 2.53 & 9.75 & 2.16 & -6.35 \\
$\widehat{P V R}_{3}^{R W}$ & 9.24 & 3.15 & 9.62 & 2.53 & -7.43 \\
$\widehat{P V R}_{4}^{R W}$ & 8.73 & 3.64 & 9.23 & 2.90 & -7.62 \\
$\widehat{P V R}_{8}^{R W}$ & 7.99 & 4.49 & 8.52 & 3.55 & -7.10
\end{tabular}

Panel B: Nonparametric Persistence Measures

\begin{tabular}{lllllll}
$\hat{R}(2)^{R W}$ & 1.02 & 0.20 & 1.01 & 0.16 & -5.09 & -4.72 \\
$\hat{R}(3)^{R W}$ & 1.00 & 0.32 & 1.01 & 0.24 & -6.70 & -6.24 \\
$\hat{R}(4)^{R W}$ & 0.99 & 0.40 & 1.01 & 0.31 & -8.37 & -7.87 \\
$\hat{R}(5)^{R W}$ & 0.95 & 0.47 & 1.00 & 0.37 & -9.14 & -8.78 \\
$\hat{R}(9)^{R W}$ & 0.89 & 0.63 & 1.00 & 0.54 & -8.61 & -7.60 \\
\hline
\end{tabular}

1"MW Z-stat" ("MWR") is the test statistic derived from the normal approximation of the Mann-Whitney $U$ test. It tests whether the distribution of persistence measures for real firm-specific earnings (reported earnings) differs from the distribution for the simulated random walk data. It is distributed $N(0,1)$. Negative values indicate that the empirical distribution is LESS persistent than the random walk. 
the two distributions. The fifth column of Table 4 contains the standardized Mann-Whitney test statistic, which is distributed $N(0,1)$ (the normal approximation). Large negative values indicate that the persistence measures for the empirical data are on average significantly smaller than those from the simulated random walk data. For the theory-based measure, the Z-statistics are significantly negative for all orders, and the strongest rejection occurs for a fourth-order model of earnings. Further, $\hat{R}(9)$ is significantly less than $\hat{R}(9)^{R W}$. Thus, the higher-order properties of earnings exhibit economically and statistically significant mean reversion. ${ }^{21}$

The tests above are in-sample in nature. We augment these with a test of out-of-sample forecasting ability by calculating the correlations between returns and out-of-sample forecast errors during 1980-1985 (see Hopwood and McKeown, 1990, for a similar analysis). The simple correlations for the random walk and ARIMA $(4,1,0)$ models are .207 and .237, respectively. Further, the partial correlations are -.002 and .118 . Subject to the usual caveats regarding OLS $t$-statistics, the forecast errors from the fourth-order model are significantly related to returns $(t=6.49)$ and have significant additional explanatory power over the random walk forecast errors $(t=3.15)$. While a full assessment of the out-of-sample forecasting ability of higher-order models is a complex issue and is beyond the scope of this article, our simple out-of-sample tests corroborate the in-sample findings.

\subsection{The Earnings Response Coefficient and the Theory-Based Persistence Measure}

Table 5 provides descriptive statistics for the response coefficients estimated using system (10)-(11) with different values of $p$. The median (mean) of $\hat{a}_{1}$ is 1.50 (2.11) while that of $\hat{a}_{4}$ is $1.85(2.68)$. Thus in contrast to the persistence measures, the response coefficient increases as $p$ increases. But the average dollar magnitude of the increase is small, and in general, the response coefficient appears less sensitive to changes in the estimation order than do the persistence measures.

We now examine $\mathrm{H} 2$, the joint hypothesis that important mean reversion emerges in the higher-order properties of the earnings generating process and that stock returns are described by classical valuation models. Table 6 reports the Spearman rank correlations between $\hat{a}_{p}$ and $\widehat{P V R}_{p}$ across firms. The diagonal of Table 6 (boldface numbers) represents those cases where the persistence measure and the response coefficient are based on the same order. Thus if Equations (10) and (11) were estimated jointly using $p$ lags of earnings

Table 5. Summary statistics for the response coefficients based on various estimation orders. Medians, interquartile ranges (IQ Range), means, and standard deviations of the earnings response coefficients $\left(\hat{a}_{p}\right)$, computed across 118 firms. Coefficients are estimated for each order for each firm using data from 1947-1985 in Equations 10 and 11.

\begin{tabular}{ccccc}
\hline Parameter & Median & IQ Range & Mean & Std Dev \\
\hline$\hat{a}_{1}$ & 1.50 & 2.44 & 2.11 & 2.27 \\
$\hat{a}_{2}$ & 1.57 & 2.79 & 2.37 & 2.62 \\
$\hat{a}_{3}$ & 1.74 & 2.90 & 2.49 & 2.57 \\
$\hat{a}_{4}$ & 1.85 & 2.90 & 2.68 & 3.41 \\
$\hat{a}_{8}$ & 2.15 & 3.05 & 3.53 & 5.75 \\
\hline
\end{tabular}


Table 6. Spearman rank correlations between the earnings response coefficient and the theorybased persistence measures, computed across 118 firms. Parameters are estimated using data from 1947-1985 for each order and each firm. Critical value ( $p$-level) for one-tailed test: $.119(.10), .152(.05), .215(.01)$, and .286(.001).

\begin{tabular}{llllll}
\hline Parameter & $\hat{a}_{1}$ & $\hat{a}_{2}$ & $\hat{a}_{3}$ & $\hat{a}_{4}$ & $\hat{a}_{8}$ \\
\hline$\widetilde{P V R_{1}}$ & $.226^{\mathrm{I}}$ & .212 & .212 & .167 & .138 \\
$\widetilde{P V R_{2}}$ & .257 & .214 & .195 & .146 & .174 \\
$\widetilde{P V R_{3}}$ & .348 & .329 & .321 & .289 & .293 \\
$\widetilde{P V R}_{4}$ & .418 & .399 & .417 & .365 & .360 \\
$\widetilde{P V R}_{8}$ & .309 & .293 & .290 & .271 &. $\mathbf{3 9 6}$ \\
\hline
\end{tabular}

${ }^{1}$ The boldface numbers indicate cases where the parameters are based on the same estimation order, $p$.

in (11), then the rank correlation between $\hat{a}_{p}$ and $\widehat{P V R}_{p}$ would be in the $p$ th position on the diagonal. With a standard error of .092 for $n=118$, most of the correlations on the diagonal are significantly greater than zero at the $1 \%$ level. The correlations increase from .226 to .365 by going from a first- to a fourth-order autoregressive model. For the eighth order, the correlation is .396 . Thus the correlations increase as $p$ increases, with most of the increase occurring by lag four. ${ }^{22}$

To address whether the increase in the correlations from using higher-order persistence measures is statistically significant, we compute several Kendall partial rank correlations. The corr $\left(\hat{a}_{1}, \widehat{P V R}_{4} \mid \widehat{P V R}_{1}\right)$ is .27 while corr $\left(\hat{a}_{1}, \widehat{P V R}_{1} \mid \widehat{P V R}_{4}\right)$ is .05. The former is significantly greater than zero at the .01 level (the $Z$-statistic is 4.12 ), while the latter is not significant at even the .10 level. If $\hat{a}_{4}$ is used instead of $\hat{a}_{1}, \operatorname{corr}\left(\hat{a}_{4}, \widehat{P V R}_{4} \mid \widehat{P V R}_{1}\right)$ is .23 while $\operatorname{corr}\left(\hat{a}_{4}, \widehat{P V R}_{1} \mid \widehat{P V R}_{4}\right)$ is .02 . Thus, the increase in the rank correlations from using higherorder persistence measures is significant. ${ }^{23}$

Collins and Kothari (1989, p. 173) express concern that using the estimated time-series parameters to compute both persistence and unexpected earnings may induce a positive correlation between $\hat{a}_{p}$ and $\widehat{P V R}_{p}$. They propose estimating the response coefficient using $\Delta X_{i t}$ instead of $e_{p i t}$ in $(10)$. However, our evidence that earnings tend to be less persistent than a random walk implies that using $\Delta X_{i t}$ may produce spurious positive correlations because $\Delta X_{i t}$ measures unexpected earnings with relatively more error for low persistence firms (see Ali and Zarowin, 1992a, p. 250). Ultimately, the magnitude of any spurious correlation becomes an empirical issue. Therefore, we estimate two additional response coefficients, the first using $\Delta X_{i t}$ as unexpected earnings in (10), and the second using $\Delta X_{i t}$ as the dependent variable in a reverse regression of (10) (see Collins and Kothari, 1989). All of the correlations between the persistence measures in Table 1 and these two response coefficients are significantly positive at the one percent level or better. Instead of diminishing, the correlations between the alternative response coefficients and $\widetilde{P V R}_{p}$ are generally larger than when $e_{p i t}$ is used in (10). ${ }^{24}$ Also, the overall pattern of the correlations suggests that using higher-order measures of earnings persistence is important. Our results do not appear to be spuriously induced by the joint estimation of (10) and (11). 


\subsection{Comparing Theory-Based and Nonparametric Measures of Persistence: Testing Classical Valuation Theory}

Table 7 contains various correlation measures for testing hypotheses $\mathrm{H} 2, \mathrm{H} 3 \mathrm{a}$, and $\mathrm{H} 3 \mathrm{~b}$. The second column of Table 7 presents the rank correlations between $\hat{a}_{p}$ and $\hat{R}(p+1)$ for $p=1,2,3,4$, and 8 . The correlations reflect response coefficients and nonparametric persistence measures based on similar estimation orders, even though the parameters are estimated separately. The correlations range from .188 to .320 . For comparative purposes, the corresponding correlations for the theory-based measure are repeated in column 1 . Both columns exhibit similar behavior. In particular, the correlations between $\hat{a}_{p}$ and $\hat{R}(p+1)$ are typically larger for higher-order estimates of persistence. Also, there is little evidence in favor of using low orders of the scaled variogram in measuring persistence. Thus as predicted by $\mathrm{H} 2$, both the theory-based and nonparametric persistence measures illustrate the importance of the higher-order properties of earnings and provide support for classical valuation theories.

More direct tests of classical valuation are obtained by comparing the theory-based and nonparametric persistence measures. The correlations in column 1 exceed those in column 2; $\overrightarrow{P V R}_{p}$ explains more of the (ranked) variation in $\hat{a}_{p}$ than does $\hat{R}(k)$, consistent with H3a. To address whether the theory-based measure has incremental explanatory power over and above that contained in the generic measure (and vice versa), the third and fourth columns of Table 7 report the partial Kendall rank correlations between the response coefficient and the two measures of persistence based on similar estimation orders..$^{25}$ Holding $\hat{R}(p+1)$ constant, the correlations between $\hat{a}_{p}$ and $\widehat{P V R}_{p}$ range from 049 to .187 . Three of the five correlations are significantly positive at the $1 \%$ level. However, holding $\widehat{P V R}_{p}$ constant, the correlations between $\hat{a}_{p}$ and $\hat{R}(p+1)$ range from -.006 to .042 , none of which are significant at the .05 level. Thus as predicted by $\mathrm{H} 3 \mathrm{~b}$, the theory-based measure exhibits incremental explanatory power but the nonparametric measure does not. This is consistent with classical valuation.

Table 7. Simple and partial rank correlations between the response coefficients and the nonparametric measure of persistence. Simple correlations capture the comovements in the response coefficients $\left(\hat{a}_{p}\right)$ and the two persistence measures $\left(\widehat{P V R}_{p}\right.$ and $\left.\hat{R}(p+1)\right)$. Partial correlations show the amount of comovement between $\hat{a}_{p}$ and one of the persistence measures while controlling for the other measure. Data are from 118 firms from 1947-1985.

\begin{tabular}{cccccc}
\hline & \multicolumn{2}{c}{ Simple Spearman Correlations } & & \multicolumn{2}{c}{ Partial Kendall Correlations } \\
\cline { 2 - 3 } \cline { 5 - 5 }$p$ & $\operatorname{Corr}\left(\hat{a}_{p}, \widehat{P V R} R_{p}\right)$ & $\operatorname{Corr}\left(\hat{a}_{p}, \hat{R}(p+1)\right)$ & & $\operatorname{Corr}\left(\hat{a}_{p}, \widehat{P V R} R_{p} \mid \hat{R}(p+1)\right)$ & $\operatorname{Corr}\left(\hat{a}_{p}, \hat{R}(p+1) \mid \widehat{P V R} R_{p}\right)$ \\
\hline 1 & $.226^{*}$ & $.218^{*}$ & $.188^{* *}$ & .049 & .042 \\
2 & $.214^{* *}$ & $.233^{*}$ & & .082 & .030 \\
3 & $.321^{*}$ & $.246^{*}$ & & $.163^{*}$ & .004 \\
4 & $.365^{*}$ & $.320^{*}$ & & $.187^{*}$ & -.006 \\
8 & $.396^{*}$ & $.179^{*}$ & .041 \\
\hline
\end{tabular}

*Significant at the .01 level, one-tailed test.

***Significant at the .05 level, one-tailed test. 


\subsection{Implications for Other Research}

The totality of our evidence indicates that long-horizon mean reversion in annual earnings emerges upon investigating the higher-order autocorrelations of earnings. This has direct implications for two issues currently being debated in finance and accounting. First, Kormendi and Lipe (1987) report a divergence between the magnitudes of the estimated return response to an earnings shock $(\hat{a})$ and the response predicted by classical valuation theory $(1+\widehat{P V R})$. As noted by Brennan $(1990$, p. 75$)$, the actual response is much less than expected. Here, Tables 1 and 5 also reveal a discrepancy. But notice that the discrepancy is reduced considerably when the mean reversion in earnings is accounted for; this is yet another example of how higher-order measures of persistence are more consistent with classical valuation theories. The rest of the divergence could easily be due to the role of alternative sources of information; Lipe's (1990) analysis shows that if market participants receive a noisy signal of $X_{t}$ at $t-1$, then $a=(1+P V R)(1-M)$, where $M$ is the "relative predictive ability" of alternative information versus past earnings. Since $0 \leq M \leq 1$, the response coefficient will be less than $1+P V R$ even if the optimal estimation order is used.26

Second, prior studies of the valuation implications of earnings have commonly used regressions of returns on the changes in earnings; returns should be related to the unexpected portion of earnings, and if earnings follow a random walk, then the earnings change equals unexpected earnings. Recent studies by Easton and Harris (1991), Ali and Zarowin (1992b), Ramesh and Thiagarajan (1990), and others recommend using both earnings changes and earnings levels as explanatory variables. The incremental importance of earnings levels in their models is due to assuming that a portion of the earnings shock is transitory. ${ }^{27}$ For cases where earnings shocks are not purely permanent or purely transitory, neither levels nor changes alone is sufficient to determine the new information in earnings, and therefore both should be included in the regression. ${ }^{28}$ Thus, the incremental explanatory power of earnings levels over differences and our finding that earnings are on average $\mathbf{4 0}$ percent less persistent than the random walk appear mutually reinforcing.

\section{Conclusion}

The time-series properties of earnings and their role in security valuation have been the focus of an impressive array of studies at the interface of finance and accounting. Investigations of the univariate time-series properties generally conclude that the earnings generating process is on average a random walk. More recent tests of the stock return response to earnings document significant cross-sectional variation in the time-series properties of earnings, although the random walk is not rejected as a reasonable approximation for the average firm. But this evidence is predominately based on the low-order autocorrelations of earnings. In light of recent evidence that the higher-order properties of other economic series exhibit significant mean reversion, we analyzed empirically the higher-order properties of earnings and their role in security valuation.

Our empirical analysis used response coefficients and theory-based and nonparametric measures of persistence, estimated over various orders, to address three main points. We 
found first that earnings are on average less persistent at long horizons than a random walk and that the difference emerges when the higher-order properties are examined. Second, both persistence measures exhibit significant correlations with the response coefficients at most orders, and the largest correlations occur for persistence measures that reflect the mean reversion in the higher-order properties of earnings. Third, the simple and partial correlations for the theory-based persistence measure are generally larger than those of the nonparametric measure. Taken as a whole, the evidence indicates that the long-horizon properties of annual earnings reveal economically and statistically significant higher-order mean reversion and that cross-firm differences in these properties are associated with differences in the return responses to earnings shocks, as predicted by classical valuation.

\section{Acknowledgments}

We thank Bill Beaver, Michael Brennan, Jim Ohlson, Katherine Schipper, Mike Stein, Paul Zarowin, and the seminar participants at the Stanford Summer Camp, the Conference on Financial Economics and Accounting, NYU, Columbia University, Vanderbilt University, and Arizona State University, and anonymous referees for their helpful suggestions. We are especially grateful to Phil Meguire for his contributions in an earlier version of this article, and to Mary Harris for her research assistance. Professor Lipe was KPMG Peat Marwick Faculty Fellow at the University of Michigan when the article was produced. An earlier article from this research project, entitled "The Implications of The HigherOrder Properties of Annual Earnings for Security Valuation," appeared in the proceedings of the Earnings Quality conference, published by the University of Oklahoma Center for Economic and Management Research (Steve Butler, ed.).

\section{Notes}

1. Prior studies have used several methods to investigate the time-series of annual earnings. Beaver (1970), Ball and Watts (1972), and Albrect, Lookabill, and McKeown (1977) investigate the average behavior of earnings for a sample of firms and find that net income exhibits behavior similar to a random walk (or a martingale). On the other hand, Lookabill (1976) and Salamon and Smith (1977) suggest that annual earnings exhibit some mean reversion. Another issue is whether earnings of different firms follow the same generating process. Albrect, Lookabill, and McKeown (1977) and Watts and Leftwich (1977) identify firm-specific time-series models and find a number of firms whose earnings series differ significantly from a random walk. The estimated models are then validated by assessing the accuracy of out-of-sample forecasts of earnings; in general, the random walk models perform somewhat better. On the other hand, studies by Brooks and Buckmaster (1976) and Lieber, Melnick, and Ronen (1983) use other criteria to uncover special cases in which earnings do not appear to follow a random walk. Also, Lev (1983) finds that the differences in autocorrelations across firms are related to economic factors such as product type (durable versus nondurable), which implies that the differences are not simply measurement errors. While this literature regarding annual earnings is most relevant for this study, readers should note that the investigations of quarterly earnings are even more extensive.

2. In his well-known book, Bill Beaver (1981, pp. 103-110) provides an early numerical illustration of the link between the time-series properties of earnings and security valuation.

3. Our adoption of the purely permanent random walk series as our baseline for discussing persistence is consistent with prior research. While our evidence is consistent with significant partial mean reversion, it does not imply full mean reversion. The latter would produce a zero increase in the long-horizon earnings forecasts instead of the average increase of 60 percent of the initial shock that we observe. 
4. Collins and Kothari (1989, table 1, p. 148) also recognize the importance of the vector valued nature of $C_{k}$ (denoted $\psi_{k}$ in their table).

5. While the analysis in Kormendi and Lipe (1987) is based on valuing the expected future net cash flows of the firm, similar implications can be derived from models which value the dividend stream (see Fama and Miller, 1972, pp. 86-88 or Ohlson, 1990).

6. In a recent survey article, Brennan $(1991$, p. 75$)$ notes that this assumption is consistent with firms paying current-period dividends equal to current-period earnings. While this is sufficient for the assumption to hold, it is not necessary. The manager can pay dividends in later periods as long as the present value of the additional payout corresponds to the present value of the revisions in expected earnings.

7. PVR has been used in other studies, including Lipe (1986, 1990), Kendall and Zarowin (1990), and Ramesh (1990). Collins and Kothari (1989) use the $\theta_{1}$ from an ARIMA $(0,1,1)$ model as their empirical measure of persistence. Papers by Easton and Zmijewski (1989) and Regier (1989) use revisions in analysts' forecasts to measure persistence. Except for Kendall and Zarowin and Ramesh, none of the prior studies uses more than two lags of differenced annual data to measure persistence.

8. See Campbell and Mankiw (1987, 1989), Cochrane (1988), Kormendi and Meguire (1990), and Liu and He (1991). Kendall and Zarowin (1990) use the scaled variogram as a diagnostic tool in selecting the best timeseries model of earnings to be used in calculating PVR. Interestingly, in 1972, Ball and Watts used the mean squared successive differences in assessing the strength of the autocorrelations in earnings; this is similar in principle to the second-order scaled variogram which we calculate.

9. The scaled variogram and the impulse response function are related. Diebold and Nerlove (1990, p. 40) show that in population,

$$
C_{\infty}=\left[\frac{R(\infty)}{\sigma_{e}^{2} / \sigma^{2}(1)}\right]^{1 / 2},
$$

where $\sigma_{e}^{2}=$ the variance of the series' shocks. For example, $C_{\infty}=R(\infty)=1.0$ for a random walk, and $C_{\infty}=R(\infty)=0.0$ for trend stationary series. For series that are less (more) persistent than the random walk, $C_{\infty}$ is greater (less) than $R(\infty)$. The equation above relates only to the asymptotes; the relation between $C_{k}$ and $R(k)$ for $k<\infty$ is more complex.

10. However, Kendall and Zarowin (1990) report that model specification has little impact on the relation between the response coefficient and estimates of $P V R$.

11. Recall that $\widehat{P V R}_{p}$ is a function of the $\hat{\phi}_{j i} \mathrm{~s}$ in (11).

12. We draw a distinction here between the theory-based and nonparametric measures because of a subtle point. As stated earlier, the existence of significant higher-order properties will result in $\hat{R}(k)$ being a more accurate representation of persistence as $k$ increases. But Equation (9) shows that $R(k)$ will also decline asymptotically for a low-order integrated autoregressive process (assuming it exhibits some mean reversion). Since evidence of a declining $\hat{R}(k)$ may or may not indicate significant higher-order properties, we choose not to include it in Hla and to only examine the asymptote in Hib. Note however that increasing $k$ will result in systematic changes in the relative cross-firm rankings of $\hat{R}(k)$ only if the higher-order properties of earnings are important. Thus the distinction above does not pertain to $\mathrm{H} 2$.

13. This sample of 118 firms is the subset of the 145 firms used in Kormendi and Lipe (1987) that have complete data from 1980-1985. The sample includes only firms with a long history of data because our purpose is to assess the long-horizon behavior of earnings. While this can induce a survivorship bias, we have no a priori reason to expect the higher-order properties of the excluded firms to be systematically more or less important. Also, to the extent that the time-series parameters shift over time, the shifts are viewed as part of the complex process that generates earnings. It is sometimes argued that time-series estimation should only use short time frames in order to increase the stability of the parameters. However, if parameter instability is a fundamental part of the economic process generating earnings, then one would want to reflect that source of instability in forecasting the future profitability of the firm. Of course, factors such as cosmetic changes in accounting principles could cause parameter shifts that do not reflect variablity in the underlying economic process. Thus it is important to compare the higher-order estimates of persistence with the response coefficients as a validation that the estimates reflect economic phenomena. Note also that Kendall and Zarowin (1990) find some stability in the estimates of persistence over time. 
14. Investigating earnings behavior over a four-year horizon with quarterly data would require a sixteenth-order time-series model. See Cochrane $(1988$, p. 914) for details regarding why increasing the nominal number of observations by sampling more frequently is not useful in investigating the long-horizon behavior of a series.

15. We would prefer to use an earnings index that is constructed on a consistent basis with the CRSP valueweighted market index. As this does not exist, we use the earnings index of the S\&P Industrials. The effects of this choice should be minimal since the correlation between the annual returns on the S\&P Industrials and the value-weighted CRSP index is .98 during this time period.

16. The medians are similar if the equations are estimated separately.

17. The ten percent interest assumption affects the cardinal values of $P V R$ but not its ordinal properties. Thus, none of our tests are sensitive to the choice of interest rates. We discuss these issues and conduct sensitivity analyses in Kormendi and Lipe (1987).

18. In a series of tests, Kormendi and Zarowin (1992) show that earnings are nonstationary, i.e., contain a unit root, even as they exhibit partial mean reversion.

19. The simulated $\widehat{P V R}_{p} s$ are based on the autoregressive parameters from estimating equation (11) by itself.

20. The predictions that $P V R_{p}=10.0$ and $R(k)=1.0$ for a random walk are based on the mean (expected) values and not the median. Table 4 shows that the mean of $\hat{R}(9)$ for the simulated data is 1.00 , but the mean of $\widehat{P V R}_{8}(8.52)$ is somewhat less than 10.0. It is not surprising that the medians are less than the expected values for the simulated data; both measures have a lower bound of zero and no upper bound and are therefore positively skewed.

21. Note that column 6 in panel B of Table 4 shows that the distribution of $\hat{R}(k)$ for reported earnings is also significantly lower than that of a random walk. Thus, the lower persistence is not an artifact of using real firm-specific earnings.

22. The importance of the higher-order persistence measures could be due to using an autoregressive model when earnings in fact follow a low-order moving average process. While specification tests do not particularly favor the moving-average form, the easiest way to address this possibility is to examine an ARIMA(0,1,1) model. The results show that $\widehat{P V R}_{M A 1}$ is 7.88 , somewhat less than $\widehat{P V R}_{1}$ but still greater than $\widehat{P V R}_{p}$ for $p \geq 2$. The rank correlations between this persistence measure and the response coefficients at order one through four and at order eight are as follows: $.242, .221, .216, .173$, and .133. Compared to Table 6 , an autoregressive model with four or more lags dominates the first-order moving average.

23. The off-diagonal correlations, presented in Table 6 for completeness, range from .138 to .418 . The maximum correlation in each column of the table indicates the estimation order of the persistence measure that is most closely related to each response coefficient. In four of the five cases, the maximum occurs for a fourth-order model. For $\hat{a}_{8}$, the maximum correlation occurs for the eighth-order persistence measure. Thus for each estimate of the return response to earnings, the strongest correlation is with a fourth-or higher-order measure of earnings persistence.

24. For example, for the response coefficient from the regression of returns on $\Delta X_{i t}$, the correlation with $\widehat{P V R}_{4}$ is .450 . When the reverse regression is used, the correlation is .426 . Both are larger than the corr $\left(\hat{a}_{4}, \widehat{P V R}_{4}\right)$ of .365 .

25. The Kendall partial correlations appear small compared to the simple Spearman correlations purely due to computational differences in the two methods. For example, the simple Kendall correlation between $\hat{a}_{4}$ and $\overrightarrow{P V R}_{4}$ is .253 ; while this is smaller than the commonly used Spearman correlation of .365 , the significance levels of both statistics are the same. We use the Kendall partial correlations because the standard errors can be computed from Maghsoodloo and Pallos (1981); we do not know of any tests for parital correlation based on the Spearman method.

26. For a similar analysis in a different context, see Quah's (1990) discussion of the undersensitivity of consumption to income shocks with respect to the permanent income hypothesis.

27. In the context of Equation (11), if we restrict $b_{j}=\bar{b}$ for all $j$ and $T=\infty$, then for $\bar{b}=0(\bar{b}=-1)$, earnings follow a random walk (white noise) process and unexpected earnings equals the change in (level of) earnings. More recently, Ohlson and Shroff (1992) use a bivariate information structure to show theoretically that the autocorrelation in earnings changes does not necessarily dictate the correct form of the returns-earnings regression. However, Lys, Ramesh, and Thiagarajan (1992) empirically examine long-window earnings and returns and provide evidence that the relative importance of earnings levels and changes does vary with persistence. 
28. Under the two restrictions on (11) in the prior note, unexpected earnings is a linear function of the level and change in earnings. Therefore, a regression of returns on these two variables is equivalent to our regression of returns on unexpected earnings in (10). Ramesh and Thiagarajan (1990) provide a detailed discussion of this issue.

\section{References}

Albrecht, W.S., L.L. Lookabill, and J.C. McKeown, "The Time-Series Properties of Annual Earnings." Journal of Accounting Research 226-244, (Autumn 1977).

Ali, A. and P. Zarowin, "Permanent Versus Transitory Components of Annual Earnings and the Association Between Abnormal Returns and Unexpected Earnings." Journal of Accounting and Economics 249-264, (June/Sept. 1992a).

Ali, A. and P. Zarowin, "The Role of Earnings Levels in Annual Earnings-Returns Studies." Journal of Accounting Research 286-296, (Autumn 1992b).

Ball, R. and R. Watts, "Some Time Series Properties of Accounting Income." Journal of Finance 663-681, (June 1972).

Beaver, W.H., "The Time Series Behavior of Earnings." Journal of Accounting Research 62-99, (Supplement 1970).

Beaver, W., Financial Reporting: An Accounting Revolution. New Jersey: Prentice Hall, 1981.

Beaver, W., R. Lambert, and S. Ryan, "The Information Content of Security Prices: A Second Look." Journal of Accounting and Economics 139-157, (July 1987).

Bernard, V.L. and J.K. Thomas, "Evidence that Stock Prices Do Not Fully Reflect the Implications of Current Earnings for Future Earnings." Journal of Accounting and Economics 305-340, (December 1990).

Brennan, M.J., "A Perspective on Accounting and Stock Prices." Accounting Review 67-79, (January 1991).

Brooks, L.D. and D.A. Buckmaster, "Further Evidence of the Time Series Properties of Accounting Income." Journal of Finance 1359-1373, (December 1976).

Campbell, J.Y. and N.G. Mankiw, "Permanent and Transitory Components in Macroeconomic Fluctuations." American Economic Review 111-117, (May 1987).

Campbell, J.Y. and N.G. Mankiw, "International Evidence on the Persistence of Economic Fluctuations." Journal of Monetary Economics 319-334, (1989).

Cochrane, J.H., "How Big Is the Random Walk in GNP?" Journal of Political Economy 893-920, (1988).

Collins, D.W. and S.P. Kothari, "An Analysis of Intertemporal and Cross-Sectional Determinants of Earnings Response Coefficients." Joumal of Accounting and Economics 143-181, (July 1989).

Diebold, F.X. and M. Nerlove, "Unit Roots in Economic Time Series: A Selective Survey." Advances in Econometrics: Co-Integration, Spurious Regressions, and Unit Roots, vol. 8 edited by T. Fomby and G. Rhodes. Greenwich, Conn.: JAI Press, 3-69, 1990.

Diebold, F.X. and G.D. Rudebush, "Long Memory and Persistence in Aggregate Output." Joumal of Monetary Economics 189-209, (1989).

Dornbusch, R. and S. Fischer, Macroeconomics. 5th ed. New York: McGraw-Hill, 1990.

Easton, P.D., T.S. Harris, and J.A. Ohlson, "Aggregate Accounting Earnings Can Explain Most of Security Returns: the Case of Long Event Windows." Journal of Accounting and Economics 119-142, (June/Sept. 1992).

Easton, P.D. and T.S. Harris, "Earnings as an Explanatory Variable for Returns." Journal of Accounting Research 19-36, (Spring 1991).

Easton, P.D. and M.E. Zmijewski, "Cross-Sectional Variation in the Stock Market Response to Accounting Earnings Announcements." Journal of Accouting and Economics 117-141, (July 1989).

Ederington, L.H., "Trend Bias in Time Series Models of Accounting Numbers: Annual Earnings and the Random Walk Hypothesis." Working paper, Washington University, August 1988.

Fama, E.F. and K.R. French, "Permanent and Temporary Components of Stock Prices." Journal of Political Economy 246-273, (1988).

Fama, E.F. and M.H. Miller, The Theory of Finance. Hinsdale, Illinois: Dryden Press, 1972.

Flavin, M., "The Adjustment of Consumption to Changing Expectations About Future Income." Journal of Political Economy 974-1009, (1981). 
Hopwood, W.S. and J.C. McKeown, "An Evaluation of Transfer-Function and Univariate Time-Series Earnings Expectation Models." Joumal of Accounting Research 313-322, (Autumn 1981).

Hopwood, W.S. and J.C. McKeown, "Evidence on Surrogates for Earnings Expectations within a Capital Market Context:" Journal of Accounting, Auditing, and Finance 339-363, (Summer 1990).

Kendall, C.S. and P. Zarowin, "Time Series Models of Earnings, Earmings Persistence and Earnings Response Coefficients." Working paper, New York University, February 1990.

Kormendi, R.C. and R.C. Lipe, "Earnings Innovations, Earnings Persistence, and Stock Returns." Journal of Business 323-345, (July 1987).

Kormendi, R.C. and P.G. Meguire, "How Big Is the Random Walk in GNP? A Multi-Country Characterization." Journal of Money, Credit and Banking 77-93, (February 1990).

Kormendi, R.C. and P. Zarowin, "The Permanent Earnings Hypothesis of Corporate Dividend Policy." Working paper, University of Michigan and New York University, September 1992.

Lev, B., "Some Economic Determinants of Time-Series Properties of Earnings." Journal of Accounting and Economics 31-48, (March 1983).

Lieber, Z., E. Melnick, and J. Ronen, "The Filtering of Transitory Noise in Earnings Numbers." Journal of Forecasting 331-350, (October 1983).

Lipe, R., "The Information Contained in the Components of Earnings." Journal of Accounting Research 37-64, (Supplement 1986).

Lipe, R., "The Relation Between Stock Returns and Accounting Earnings Given Alternative Information," Accounting Review 49-71, (January 1990).

Liu, C.Y. and J. He, "A Variance-Ratio Test of Random Walks in Foreign Exchange Rates." Journal of Finance 773-785, (June 1991).

Lookabill, L.L., "Some Additional Evidence on the Time Series Properties of Accounting Earnings." Accounting Review 724-738, (October 1976).

Lys, T, K. Ramesh, and S.R. Thiagarajan, "The Role of Earnings Levels vs Earnings Changes in Explaining Stock Returns: Implications from the Time Series Properties of Earnings." Working paper, Northwestern University, July 1992.

Maghsoodloo, S. and L.L. Pallos, "Asumptotic Behavior of Kendall's Partial Rank Correlation Coefficient and Additional Quantile Estimates." Journal of Statistical Computer Simulation 41-48, (1981).

Miller, M. and K. Rock, "Dividend Policy Under Asymmetric Information." Journal of Finance 1031-1051, (December 1985).

Ohlson, J.A., "Price-Earnings Ratios and Earnings Capitalization Under Uncertainty." Journal of Acconting Research 141-154, (Spring 1983).

Ohlson, J.A., "A Synthesis of Security Valuation Theory and the Role of Dividends, Cash Flows, and Earnings." Contemporary Accounting Research 648-676, (Spring 1990).

Ohlson, J.A. "Accounting Earnings, Book Value, and Dividends: The Theory of the Clean Surplus Equation (Part D)." Working paper, Columbia University, 1989.

Ohlson, J.A. and P.K. Shroff, "Changes vs. Levels in Earnings as Explanatory Variables for Returns: Some Theoretical Considerations." Working paper, Columbia University, June 1992.

Quah, D., "Permanent and Transitory Movements in Labor Income: An Explanation for 'Excess Smoothness' in Consumption." Journal of Political Economy 449-475, (June 1990).

Ramesh, K., "The Existence of a Unit Root in Earnings as a Determinant of the Price-Earnings Relation." Working paper, Michigan State University, March 1990.

Ramesh, K. and S.R. Thiagarajan, "Value Relevance of Earnings Levels." Working paper, Northwestern University, November 1990.

Regier, P., "Relations Between Earnings Innovations, Return Responses and Revisions in Analysts' Quarterly Earnings Forecasts: Extensions and Further Evidence." Working paper, Arizona State University, August 1989.

Salamon, G.L. and E.D. Smith, "Additional Evidence on the Time Series Properties of Reported Earnings Per Share: Comment." Joumal of Finance 1795-1801, (December 1977).

Watts, R. and R. Leftwich, "The Time Series of Annual Accounting Earnings." Journal of Accounting Research 253-271, (Autumn 1977). 